\title{
EFFECT OF SELECTED POLYMERS ON DISSOLUTION AND STABILIZATION OF AMORPHOUS FORM OF MELOXICAM
}

\author{
RANA OBAIDAT ${ }^{*}$, BASHAR AL-TAANI, HANAN AL-QURAAN
}

Department of Pharmaceutical Technology, Faculty of Pharmacy, Jordan University of Science and Technology, Irbid, Jordan Email: obeidatrana@yahoo.com

Received: 22 Mar 2017 Revised and Accepted: 13 Jul 2017

ABSTRACT

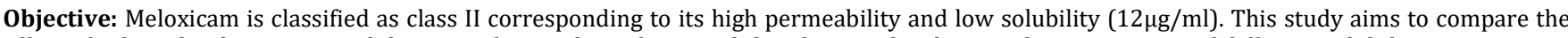
effect of selected polymers on stabilization of amorphous form, and dissolution of meloxicam by preparation of different solid dispersions using selected polymers (chitosan oligomers, polyvinylpyrrolidone K30, and polyethylene glycols).

Methods: These solid dispersions were prepared using two different methods; solvent evaporation method for the two molecular weights chitosan carriers (16 and $11 \mathrm{KDa}$ ) and polyvinylpyrrolidone-K30 and melting method for the two different molecular weights polyethylene glycol (4000 and 6000 ). The physicochemical properties of solid dispersions were analyzed using differential scanning calorimetry, Fourier transform infra-red analysis, Powder X-ray diffraction, and scanning electron microscopy. Selected dispersions were then compared to two selected marketed drugs (Mobic $®$ and Moven $囚)$.

Results: Best dissolution rates were obtained for both polyvinylpyrrolidone-K30 and polyethylene glycol 6000 , followed by chitosan 16 kDa, chitosan $11 \mathrm{kDa}$, and polyethylene glycol 4000. Increasing polymeric ratio increased dissolution rate except for chitosan. Precipitation of the drug as amorphous form occurred in chitosan and polyvinylpyrrolidone-K30 dispersions, while no change in crystallinity obtained for polyethylene glycol dispersions. Failure of polyvinylpyrrolidone-K30 in the maintenance of stability during storage time was observed while re-crystallization occurred in chitosan-based dispersions, which ends with preferences to polyethylene glycol dispersions. After comparing the release of selected dispersions with the two selected polymers; all dispersions got a higher release than that of the two marketed drugs release.

Conclusion: The dissolution profile of meloxicam has been increased successfully in a reproducible manner.

Keywords: Meloxicam, Polymers, Dispersions, Amorphous

(C) 2017 The Authors. Published by Innovare Academic Sciences Pvt Ltd. This is an open access article under the CC BY license (http://creativecommons.org/licenses/by/4.0/) DOI: http://dx.doi.org/10.22159/ijpps.2017v9i9.18621

\section{INTRODUCTION}

Meloxicam is a part of the oxicam group (fig. 1) of a non-steroidal anti-inflammatory drug. It has an antipyretic, analgesic action and mainly used for the treatment of rheumatoid arthritis. Meloxicam has a poor aqueous solubility of approximately $12 \mu \mathrm{g} / \mathrm{ml}$ which will lead to poor dissolution rate and poor absorption $[1,2]$.<smiles>Cc1cnc(NC(=O)C2=C(O)c3ccccc3S(=O)(=O)N2C)s1</smiles>

Fig. 1: Chemical structure of meloxicam [3]

Discovering strategies to enhance the solubility and dissolution of poorly soluble drugs is a primary challenge in the pharmaceutical field. Various techniques have been used for enhancing drug's dissolution rate. One of these methods was solid dispersion (SD) method [4-8]. It is an effective method used in improving the dissolution of drugs. It can be made only by dispersing a drug in a carrier matrix. SD may improve the dissolution of various drugs by improving drug wettability, reducing drug particle size and converting the drug into an amorphous state. Many methods were used in preparing SD such as; Fusion method, Solvent method, Hot melt extrusion, Lyophilization, Spray drying, Kneading and supercritical fluid technique $[5,6,9]$.

Many polymers can act as hydrophilic carriers in SD preparation. These include chitosan [10], Polyvinylpyrrolidone K30 (PVP K30) [11] and polyethylene glycol (PEG) [12]. Chitosan is a biopolymer that is obtained through alkaline $\mathrm{N}$-deacetylation of chitin. Different grades of chitosan are available, with variable molecular weights (50-2000 kDa), viscosities and various degrees of deacetylation. Polyvinylpyrrolidone (PVP) which is also called povidone; it is a polymeric lactam that is made of $\mathrm{N}$ vinylpyrrolidone monomers. It is readily soluble in water and available in different $\mathrm{K}$ values, which is an indication of the ranges of the mean molecular weights. Polyethylene glycol (PEG) is a synthetic polymer which is available in a range of molecular weights (1500-20000 g/mol). It showed ability in the enhancement of solubility and wettability of many drugs.

The primary aims of this study were to compare the effect of selected polymers on stabilization of drug's amorphous form, and on the enhancement of dissolution of meloxicam. Solid dispersions were prepared using chitosan, PVP K30, and PEG. Also, this study aimed to evaluate the effect of molecular weight of the polymer. Two molecular weights were used from chitosan (chitosan $16 \mathrm{kDa}$ and chitosan 11 $\mathrm{kDa}$ ), and PEG (PEG 4000 and PEG 6000). Dispersions of the different drug to polymer ratios were prepared. The prepared SDs were then characterized using different characterization procedures. In vitro Release studies were then performed for pure meloxicam and the prepared SDs, then a comparison with two selected marketed drugs (Mobic $\AA$ and Moven $囚$ ) was conducted. Finally, accelerated stability studies were conducted for the prepared SDs.

\section{MATERIALS AND METHODS}

\section{Materials}

Meloxicam was kindly donated by the Jordanian pharmaceutical manufacturing company, Naor, Jordan. Raw chitosan polymer (600 $\mathrm{kDa}$ ) was obtained from Shanghaihanshare Industry Co. Ltd, China. Hydrochloric acid (37\%; w/w) was supplied by biosolve, France. Absolute ethanol (96\%) was provided by solvochem, holland. Methanol (HPLC grade) and dichloromethane (DCM; HPLC Grade) 
were provided by Fisher chemical, UK. Sodium tripolyphosphate (STPP) was supplied by Sigma-Aldrich, USA. Polyvinylpyrrolidone K30 (PVP K30) was supplied by Aldrich Chemistry, USA. PEG (4000 and 6000) polymers were supplied by fluka biochemika, Switzerland. Potassium bromide (IR spectroscopy grade), sodium hydroxide (granulated, synthesis grade) and potassium dihydrogen phosphate (extra pure) were supplied by scharlau chemie, Spain. Nylon membrane filters- $0.45 \mu \mathrm{m}$ were supplied by bonnaagela technologies, USA. Distilled water was used in all experiments. All chemicals were used as supplied without further modifications except for chitosan. Chitosan was prepared as Obeidat et al. (2010) to prepare two different molecular weights (chitosan 16 and chitosan $11 \mathrm{kDa}$ ). Further crosslinking was performed according to obaidat et al.[13].

\section{Methods}

\section{Preparation of solid dispersions}

Table 1 summarizes the prepared SDs showing the different drug: polymer ratios and the methods used for preparation.

Table 1: The prepared SDs and the method used

\begin{tabular}{llll}
\hline SD & Polymer & Drug: polymer ratio (W: W) & Method \\
\hline SD1 & Chitosan 16 KDa & $1: 9$ & Solvent Evaporation \\
SD2 & Chitosan 16 KDa & $2: 8$ & Solvent Evaporation \\
SD3 & Chitosan 16 KDa & $3: 7$ & Solvent Evaporation \\
SD4 & Chitosan 11 KDa & $1: 9$ & Solvent Evaporation \\
SD5 & Chitosan 11 KDa & $2: 8$ & Solvent Evaporation \\
SD6 & Chitosan 11 KDa & $3: 7$ & Solvent Evaporation \\
SD7 & PVP & $1: 9$ & Solvent Evaporation \\
SD8 & PVP & $2: 8$ & Solvent Evaporation \\
SD9 & PVP & $3: 7$ & Solvent Evaporation \\
SD10 & PEG 4000 & $1: 9$ & Melting \\
SD11 & PEG 4000 & $2: 8$ & Melting \\
SD12 & PEG 4000 & $3: 7$ & Melting \\
SD13 & PEG 6000 & $1: 9$ & Melting \\
SD14 & PEG 6000 & $2: 8$ & Melting \\
SD15 & PEG 6000 & $3: 7$ & Melting \\
\hline
\end{tabular}

The ratios prepared were (w/w; 1:9, 2:8, and 3:7; meloxicam: chitosan) according to the following

\section{Meloxicam in chitosan SDs using rotary evaporator}

Meloxicam was dissolved in a suitable amount of dichloromethane loaded in the final step of chitosan carrier preparation (in 100\% ethanol); stirring for $15 \mathrm{~min}$ was applied to allow homogeneous distribution of the drug. After that chitosan carrier loaded with meloxicam was dried using rotary evaporator at $90 \mathrm{rpm}$ and $95{ }^{\circ} \mathrm{C}$ for $20 \mathrm{~min}$.

\section{Meloxicam in PVP SDs using vacuum oven}

Meloxicam was dissolved in $10 \mathrm{ml}$ of dichloromethane and PVP was dissolved in approximately $10 \mathrm{ml}$ of ethanol then meloxicam solution was poured over PVP solution then the mixed solution was placed on a magnetic stirrer until a clear solution was obtained. The solution was then transferred into a Petri-dish and dried by using vacuum oven at $110^{\circ} \mathrm{C}$ for $15 \mathrm{~min}$.

\section{Meloxicam in PEG SDs by melting method}

Suitable amounts of meloxicam were added to PEG (PEG 4000 or PEG 6000), after being melted at approximately $63{ }^{\circ} \mathrm{C}$ or $65{ }^{\circ} \mathrm{C}$ respectively using a water bath; the homogeneous dispersion was assured by an efficient stirring.

\section{Preparation of physical mixtures}

Physical mixtures (PMs) of meloxicam with different polymers were prepared. Physical mixture of meloxicam with each polymer (chitosan $16 \mathrm{kDa}$, chitosan $11 \mathrm{kDa}$, PVP, PEG 4000, PEG 6000) were made at different drug to polymer weight ratios (1:9, 2:8, and 3:7) by weighing (0.1g: $0.9 \mathrm{~g}, 0.2 \mathrm{~g}: 0.8 \mathrm{~g}$ and $0.3 \mathrm{~g}: 0.7 \mathrm{~g}$, respectively).

PMs were prepared by mixing the mentioned amounts of meloxicam and the selected polymer homogeneously using mortar and pestle without any trituration for few seconds. The mixtures were then sieved using (180 and $300 \mu \mathrm{m})$-sieves and then PMs were stored in a desiccator for further use.

\section{Characterization procedures}

Drug content and yield value determination

Samples of $10 \mathrm{mg}$ of each SD were dissolved in $25 \mathrm{ml}$ of methanol and then stirred by a magnetic stirrer for $15 \mathrm{~min}$ to ensure the total amount of drug present in the sample was completely dissolved. After that specific dilution was made to have certain concentrations and then filtered via a $45 \mu \mathrm{m}$ filter, and analyzed by UV method [14]. Drug content $\%$ and "Yield value" were calculated using the following equations [15]:

$$
\begin{gathered}
\text { Drug content } \%=\frac{\text { Actual drug content }}{\text { Theoritical drug content }} * 100 \% \\
\text { Yield value } \%=\frac{\text { Weight of prepared solid dispersion }}{\text { (weight of drug+weight of polymer) }} * 100 \%
\end{gathered}
$$

\section{Differential scanning calorimetry (DSC)}

DSC thermograms were recorded for the raw materials, PMs $(1: 9$, 2:8 and 3:7 meloxicam: polymer ratios), and the SDs (1:9, 2:8 and 3:7 meloxicam: polymer ratios)(using differential scanning calorimeter (DSC)-(Nietzsche, Germany). Approximately $5 \mathrm{mg}$ of each sample was heated in a sealed aluminum pan from 30 to $300^{\circ} \mathrm{C}$ at a heating rate of $10^{\circ} \mathrm{C} / \mathrm{min}$ under a stream of nitrogen. An empty sealed pan was used as a reference.

\section{Fourier transform infrared spectroscopy (FTIR)}

Fourier transform infrared (FTIR) spectra of raw materials, PMs (1:9, 2:8 and 3:7 meloxicam: polymer ratios) and SDs (1:9, 2:8 and 3:7 meloxicam: polymer ratios) were obtained by blending the sample with small amount of potassium bromide ground with mortar and pestle to get homogenous sample; using fourier transform infra-red spectroscopy (FT-IR) model IR-affinity-1 (Shimadzu, Japan). The scanning range was $4750-500 \mathrm{~cm}^{-1}$.

\section{Powder X-ray diffraction analysis (PXRD)}

PXRD of raw materials, PMs (1:9, 2:8 and 3:7 meloxicam: polymer ratios) and SDs (1:9, 2:8 and 3:7 meloxicam: polymer ratios) were recorded using Ultima IV powder X-ray diffractometer (Riguka, Japan). The samples were analyzed in the $2 \theta$ angle range of 0 to 8 . Results were confirmed by excluding dilution effect by comparison with related ratios of PMs.

\section{Scanning electron microscopy (SEM)}

SEM images were obtained for raw materials, PM (1:9; meloxicam: polymer ratio), and the SDs (1:9; meloxicam: polymer ratio) at different specified magnifications operating at $2.00 \mathrm{KV}$ using environmental scanning electron microscopy (Quanta 450 FEG- 
USA/EEU). After placing the samples on stubs, it was coated with platinum using Emitech K550X Sputtercoater under vacuum to obtain a conductive film.

\section{In vitro drug release studies}

Meloxicam dissolution from samples and commercial products (Moven $\AA$ and Mobic $\AA$ ) were studied. The SDs equivalent to $15 \mathrm{mg}$ meloxicam was filled manually into a hard gelatin capsule (size (0)). The dissolution tests were performed using USP apparatus II (rotating paddle) at $75 \mathrm{rpm}$ and $37{ }^{\circ} \mathrm{C}$ using $900 \mathrm{ml}$ of $0.2 \mathrm{M}$ of potassium phosphate buffer with adjusted $\mathrm{pH}$ of 7.5. At predetermined time intervals, $10 \mathrm{ml}$ aliquot was taken, filtered through $0.45 \mu \mathrm{m}$ and analyzed by UV spectrophotometer at $\lambda \max$ of $361.4 \mathrm{~nm}$. An equal volume of dissolution media was replaced to maintain the volume of dissolution medium[16]. Comparison between the pure meloxicam with prepared dispersions is shown in fig. 6. On the same figure, the comparison between each of the two marketed drugs (Mobic $\AA$ and Moven $\AA$ ) and the highest release profiles of each SDs is shown while table 3 presenting the p-values, by the assumption of the p-value of 0.05 . One one-tailed test was used to investigate if each selected formulation provided significantly higher release (one direction effect) profile than each marketed drugs (Mobic $($ and Moven $®)$. Also, model fitting was performed to dissolution results according to Obaidat et al. $[15,17]$ to zero-order, Higuchi model, and korsmeyer-peppas model [18].

\section{Stability studies}

The SD preparations of 1:9 (w/w, meloxicam: polymer) ratio were subjected to accelerated stability studies for the period of $3 \mathrm{mo}$ in stability chambers (memmert, Germany) at two different conditions, the first one at $30 \pm 2{ }^{\circ} \mathrm{C}$ with $75 \pm 5 \% \mathrm{RH}$ and the second one at $40 \pm 2$ ${ }^{\circ} \mathrm{C}$ with $75 \pm 5 \% \mathrm{RH}$.

The samples were withdrawn after the three months to be tested visually, physically (PXRD analysis) and chemically (drug content and HPLC analysis). Validated HPLC analysis was performed using HPLC apparatus, model LT0711006, Shimadzu. The chromatographic column used was ACE C18 (250*4.6 mm, $5 \mu \mathrm{m})$, the mobile phase composed of methanol: Phosphate buffer $(\mathrm{pH}=6)$ (55:45), the flow rate was $1 \mathrm{ml} / \mathrm{min}$, the injection volume was $20 \mu \mathrm{l}$, and the detection wavelength was $361.4 \mathrm{~nm}$ [19].

\section{RESULTS}

\section{Drug content and yield determination}

In general, good drug content was achieved for all preparations having values higher than $83.9 \%$ (table 2). The highest percentage was achieved for PEGs with PEG 6000 having approximately the highest values. Also, the lowest drug content value was obtained with PVP polymer.

Table 2: Drug: polymer ratio, drug content \%, and yield values \% of the different meloxicam solid dispersions (SDs). Results are represented as a mean value of three readings \pm SD

\begin{tabular}{|c|c|c|c|}
\hline & Drug: polymer ratio (w/w) & Drug content $\% \pm S D$ & Yield $\% \pm$ SD \\
\hline SD1 & $1: 9$ & $85.45 \% \pm 1.5$ & $76.10 \pm 8.60$ \\
\hline SD2 & $2: 8$ & $93.46 \% \pm 0.34$ & $75.70 \pm 5.20$ \\
\hline SD3 & $3: 7$ & $93.28 \% \pm 0.57$ & $80.03 \pm 1.70$ \\
\hline SD4 & $1: 9$ & $85.70 \% \pm 1.2$ & $71.50 \pm 12.00$ \\
\hline SD5 & $2: 8$ & $85.10 \% \pm 2.5$ & $65.57 \pm 9.10$ \\
\hline SD6 & $3: 7$ & $88.90 \% \pm 1.8$ & $79.85 \pm 6.20$ \\
\hline SD7 & $1: 9$ & $96.04 \% \pm 1.3$ & $68.36 \pm 4.74$ \\
\hline SD8 & $2: 8$ & $94.80 \% \pm 1.2$ & $65.66 \pm 6.03$ \\
\hline SD9 & $3: 7$ & $93.07 \% \pm 1.6$ & $64.66 \pm 3.4$ \\
\hline SD10 & $1: 9$ & $97.90 \% \pm 2.2$ & $93.06 \% \pm .01$ \\
\hline SD11 & $2: 8$ & $103.20 \pm 0.6$ & $94.88 \pm 0.01$ \\
\hline SD12 & $3: 7$ & $104.00 \pm 2.4$ & $94.54 \pm 0.01$ \\
\hline SD13 & $1: 9$ & $99.40 \pm 0.55$ & $96.53 \pm 0.02$ \\
\hline SD14 & $2: 8$ & $97.63 \pm 2.0$ & $93.06 \pm 0.02$ \\
\hline SD15 & $3: 7$ & $94.30 \pm 1.4$ & $92.81 \pm 0.02$ \\
\hline
\end{tabular}
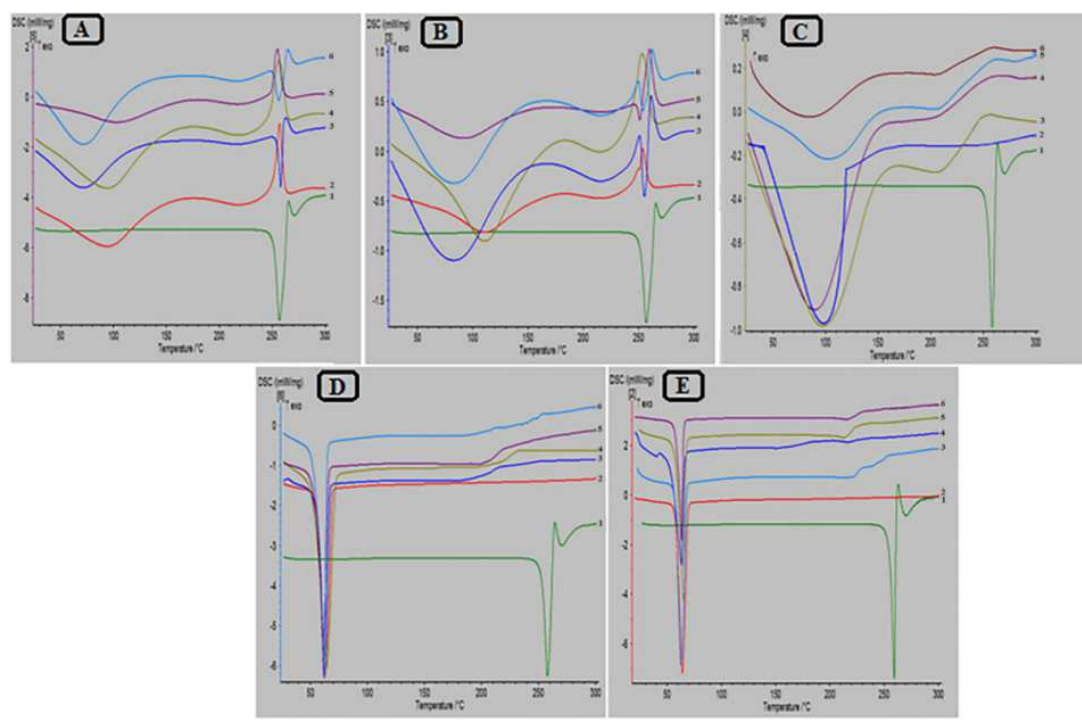

Fig. 2: DSC thermograms of A: (1) Pure meloxicam, (2) Chitosan 16 KDa, (3) PM of (3:7; meloxicam: chitosan 16 KDa), (4) SD1, (5) SD2, and 6) SD3; B: (1) Pure meloxicam, (2) Chitosan 11KDa, (3)) PM of (3:7; meloxicam: chitosan 11 KDa), (4) SD4, (5) SD5, and 6) SD6; C: (1) Pure meloxicam, (2)PVP, (3) Physical mixture of (3:7; meloxicam: PVP) (4) SD 7, (5) SD8, and (6) SD9; D: 1) Pure meloxicam, 2) PEG 4000, 3) physical mixture of (3:7; meloxicam: PEG 4000), 4) SD10, 5) SD11, and 6) SD12; and E: (1) pure meloxicam, (2) PEG6000, (3) PM of (3:7; meloxicam: PEG 6000) (4) SD 13, (5) SD14, and (6) SD15. Samples named according to table 1 


\section{Differential scanning calorimetry (DSC)}

The thermogram of pure meloxicam was characterized (fig. 2) by a single, sharp endothermic peak at $259.3^{\circ} \mathrm{C}$ and a second exothermic peak at $265^{\circ} \mathrm{C}$. While thermograms of chitosan oligomers showed the presence of two peaks. The first ranged from $\left(52-137{ }^{\circ} \mathrm{C}\right)$ followed by a second exothermic peak at the range of $\left(251-261^{\circ} \mathrm{C}\right)$. Thermogram of PVP K30 showed a broad endothermic peak (50-150 ${ }^{\circ} \mathrm{C}$ ). Sharp endothermic peaks appeared at $64.4{ }^{\circ} \mathrm{C}, 65^{\circ} \mathrm{C}$ for PEGs. It can be seen that meloxicam peak disappeared in PMs and SDs of PVP and PEGs. Meloxicam peak appeared in PMs of chitosan and some SDs. However, it disappeared in chitosan SDs of $16 \mathrm{kDa}$ in two ratios ((1:9), (2:8)), as well as for chitosan $11 \mathrm{kDa}$ carrier in the ratio (2:8).

\section{Fourier transform infrared spectroscopy (FTIR)}

It can be indicated from the FTIR spectra (fig. 3) of pure meloxicam, that it had a characteristic peak of N-H stretching vibration at 3290.3 $\mathrm{cm}^{-1}$, of $\mathrm{C}=\mathrm{N}$ stretching vibrations at $1620.21 \mathrm{~cm}^{-1}$ and $\mathrm{S}=0$ stretching vibrations at $1153.43 \mathrm{~cm}^{-1}, 1550.77 \mathrm{~cm}^{-1}$ and $1531 \mathrm{~cm}^{-1}$ [15].

Chitosan carriers had the same spectra with characteristic peaks at $3701.4 \mathrm{~cm}^{-1}$ to $2366.66 \mathrm{~cm}^{-1}$. These were related to $\mathrm{O}-\mathrm{H}$ and $\mathrm{N}-\mathrm{H}$ stretching respectively, at $2923 \mathrm{~cm}^{-1}$ for the symmetric $\mathrm{CH} 2$ stretching attributed to the pyranose ring, peaks at 1041 and 1068 $\mathrm{cm}^{-1}$ were for C-0 stretching. The area between $1627.92 \mathrm{~cm}^{-1}$ and
$1541.2 \mathrm{~cm}^{-1}$ peaks was related to $\mathrm{NH} 2$ scissoring vibrations, and a peak at $1155.36 \mathrm{~cm}^{-1}$ was for the anti-symmetric stretch of C-O-C bridge bond. Spectra of PVP showed major bands at $1658.78 \mathrm{~cm}^{-1}$ $(\mathrm{C}=0)$, at $2949.16 \mathrm{~cm}^{-1}(\mathrm{C}-\mathrm{H}$ stretch $)$, at $3446.79 \mathrm{~cm}^{-1}(\mathrm{O}-\mathrm{H}$ stretching), at 1292.31 (C-N stretching) and at 3290.3 (N-H stretching). Spectra of the two molecular weights PEGs showed that they have the same spectra. The Spectra showed major peaks at $2887 \mathrm{~cm}^{-1}$ was for C-H stretching; $1107 \mathrm{~cm}^{-1}$ was for $\mathrm{C}-\mathrm{O}$ stretching, and $3425 \mathrm{~cm}^{-1}$ was for $\mathrm{O}-\mathrm{H}$ stretching.

Spectra of chitosan PMs (3:7) indicated that there was no or weak interactions. Spectra of chitosan SDs showed a disappearance of $\mathrm{N}-\mathrm{H}$ peak of meloxicam (at $3290.3 \mathrm{~cm}^{-1}$ ) at (1:9) ratio, indicating the formation of a strong hydrogen bonding between meloxicam and chitosan. Also, it worth mentioning that increasing the ratio of meloxicam caused the reappearance of that peak. The three characteristic peaks disappeared for meloxicam in the PVP SDs of the lower ratio (1:9) which are 3290.3 (for N-H stretching), 1620.1 (for $\mathrm{C}=\mathrm{N}$ vibrations), and 1153.4 (for $\mathrm{S}=0$ vibrations). The peak at $3290.3 \mathrm{~cm}^{-1}$ appeared at 3:7 meloxicam: PVP, so at 3:7 of meloxicam: PVP ratio SD; the N-H stretch peak appeared but in lower intensity than that of the pure drug, so the interaction will be weakened. The characteristic peaks of meloxicam appeared in the spectra of PEG SDs. A significant decrease in the intensity of $\mathrm{N}-\mathrm{H}$ and $\mathrm{S}=\mathrm{O}$ stretching and vibration peaks and also there was a shift to higher wave number and a decrease in the intensity of $\mathrm{C}=\mathrm{N}$ peak.

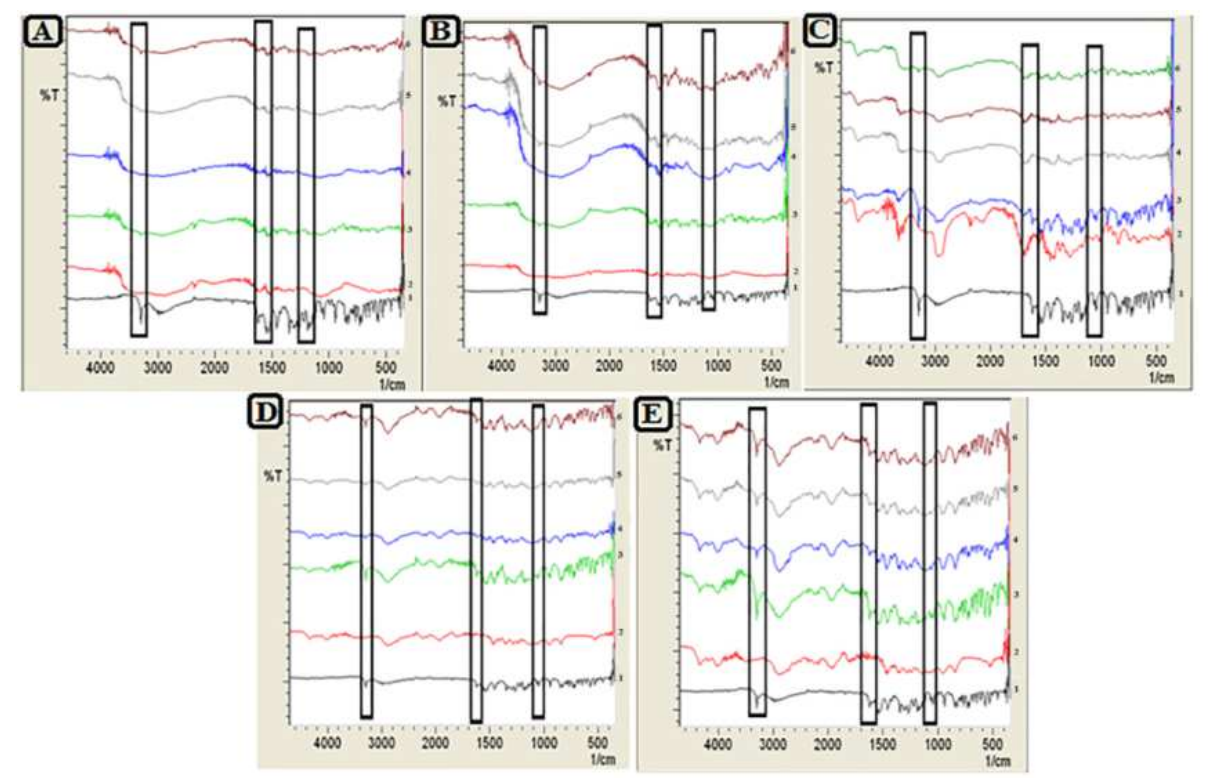

Fig. 3: FTIR spectra of A: 1) Pure meloxicam, 2) Chitosan 16 KDa, 3) (3:7; meloxicam: chitosan 16 KDa, 4) SD1, 5)SD2, and 6) SD3; B: 1) Pure meloxicam, 2) Chitosan 11 KDa, 3) PM of (3:7; meloxicam: chitosan 11 KDa), 4) SD4, 5) SD5, and 6) SD6; C: 1) Pure meloxicam, 2) PVP, 3) PM of (3:7; meloxicam: PVP), 4) SD7, 5) SD8, and 6) SD9; D: of 1) Pure meloxicam, 2) PEG 4000, 3) physical mixture of (3:7; PEG 4000), 4) SD10, 5) SD11, and 6) SD12; and E: 1) Pure meloxicam, 2) PEG6000, 3) PM of (meloxicam: PEG 6000), 4) SD13, 5) SD14, and 6) SD15. Samples named according to table 1

\section{Powder X-ray diffraction analysis (PXRD)}

PXRD of pure meloxicam (fig. 4) indicated intensive and sharp X-ray peaks. The main peaks located at $2 \Phi$ equal to $6.579^{\circ}$, $11.367^{\circ}$, $14.997^{\circ}, 18.659^{\circ}$, and $25.895^{\circ}$.

PXRD of chitosan showed two main peaks at $2 \Phi$ equals to $15^{\circ}$ and 25‥ PXRD of PVP appeared that PVP was completely amorphous without any characteristic peaks. PXRDs of PEGs indicated that PEG4000 has two characteristic peaks at $2 \theta$ of $19.35^{\circ}$ and $23.5^{\circ}$ showing a relative crystallinity, and PEG 6000 also showed two peaks at $19.11^{\circ}$ and $23.297^{\circ}$.

In the PXRD of PMs, the characteristic peak of the drug appeared. While that characteristic peak disappeared only in the PXRD of (1:9; meloxicam: PVP) and (1:9; meloxicam: chitosan $16 \mathrm{KDa}$ ) SDs.

\section{Scanning electron microscopy (SEM)}

It can be seen that meloxicam (fig. 5) had a crystalline rectangular shape of its particles that are agglomerated in bundles and also had a smooth surface.

It can be seen that chitosan had a rough, wrinkled surface, but there were some differences in the wall shape because of crosslinking with uniformity in size. Also, it can be observed that higher molecular weight chitosan (16 kDa) exhibits spherical shape. The morphology of raw PVP indicated irregular rounded spherical shape. While for PEGs, it appeared to be in crystalline agglomerates form with irregularity in shape and size.

Both meloxicam and the polymer appeared in PMs. Considering SDs, it can be seen that the drug was completely incorporated inside 
chitosan $16 \mathrm{kDa}$ carrier and PVP. On the other hand, drug deposition was observed on the surface of chitosan $11 \mathrm{kDa}$. However, the partial inclusion of the drug inside PEGs polymers was observed.
Although the drug was present in crystalline form; it appeared that it was incorporated on the surface in particular manner; which was expected to decrease drug aggregation.

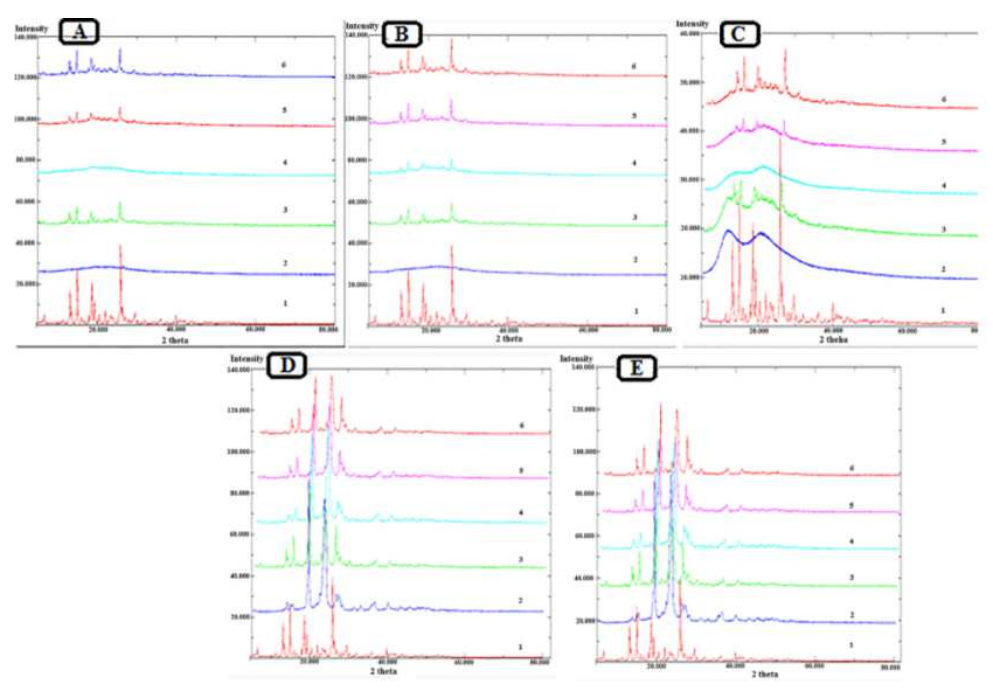

Fig. 4: PXRD of A: 1) Pure meloxicam, 2) Chitosan 16 KDa, 3) PM of (3:7; meloxicam: chitosan 16 KDa), 4) SD1, 5)SD2, and 6) SD3; B: 1) Pure meloxicam, 2) Chitosan 11 KDa, 3) PM of (3:7; meloxicam: chitosan 11 KDa), 4) SD4, 5) SD5, and 6) SD6; C: 1) Pure meloxicam, 2) PVP, 3) PM of (3:7; meloxicam: PVP), 4) SD7, 5) SD8, and 6) SD9; D: 1) Pure meloxicam, 2) PEG 4000, 3)PM of (3:7; meloxicam: PEG 4000), 4) SD10, 5) SD11, and 6) SD12; and E: 1) Pure meloxicam, 2) PEG 6000, 3)PM of (3:7; meloxicam: PEG 6000), 4) SD13, 5) SD14, and 6) SD15. Samples named according to table 1

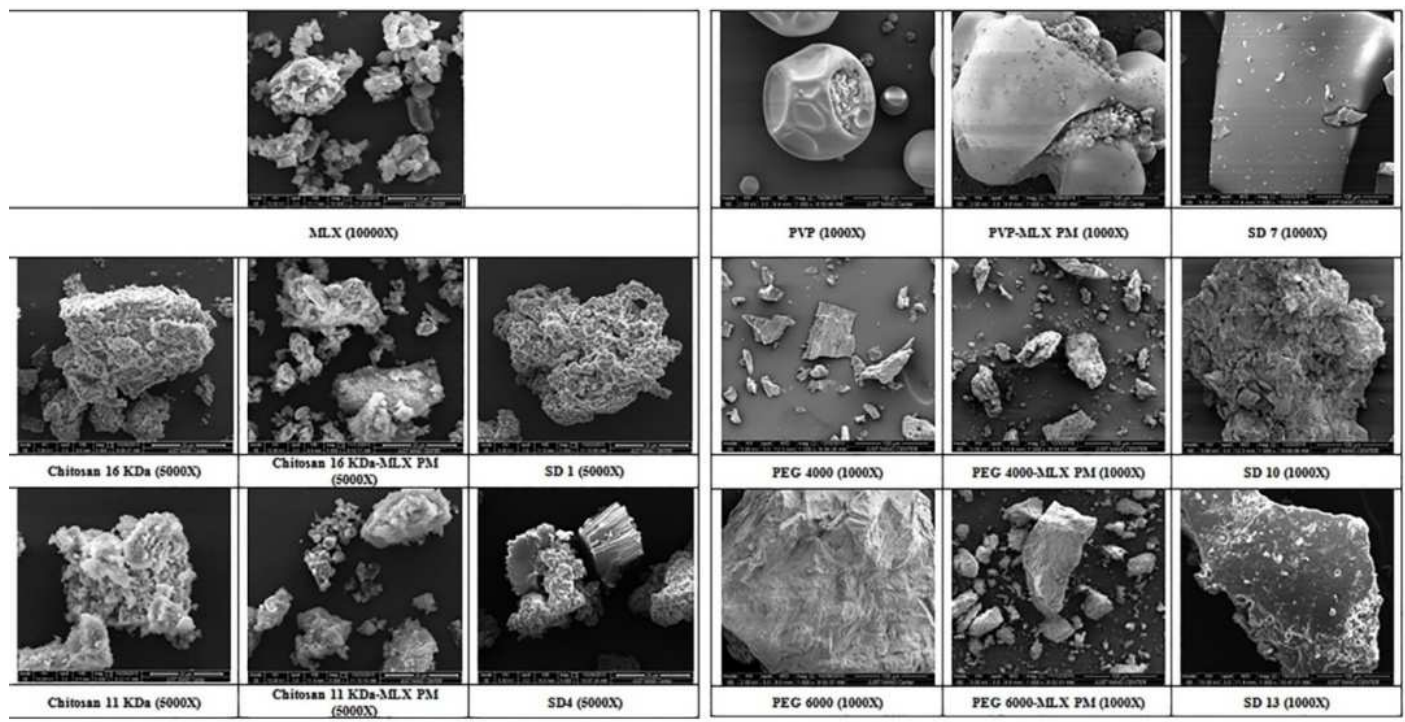

Fig. 5: SEM images of raw material, physical mixtures (1:9, meloxicam: polymer) and the prepared solid dispersions (SD1(1:9, meloxicam: chitosan $16 \mathrm{KDa})$, SD4(1:9, meloxicam: chitosan $11 \mathrm{KDa})$, SD7(1:9, meloxicam: polyvinylpyrrolidone), SD10(1;9, meloxicam: PEG 4000), and SD13(1:9, meloxicam: polyethylene glycol 6000). Samples named according to table 1

\section{In vitro drug release studies}

The dissolution of meloxicam (fig. 6) was relatively small, and apparently, the particles showed floating on the surface of the media (approximately 33\% after $210 \mathrm{~min}$ ). It can also be seen that all PMs that were prepared by different polymers showed a small enhancement in the release of the drug. Significant enhancement of dissolution can be observed for prepared SDs. It can also be seen that by decreasing chitosan to drug ratio; the release increased. This was attributed to the fact that by decreasing the chitosan ratio; the media's viscosity would decrease and this will increase the release rate [20]. So, it can be seen that the 3:7 ratio showing the maximum dissolution rate in both chitosan-based SDs with chitosan $16 \mathrm{kDa}$ exhibits the highest rate.

For PVP and PEG SDs, a higher release was obtained for higher ratios. The dissolution rate of PEG 4000 SDs of (1:9) was apparently lower than that of the PEG 6000 SDs of the same ratio. The maximum percentage of release was achieved with PVP and PEG 6000 with values reached

$79 \%$ followed by $77 \%$ for $16 \mathrm{KDa}$ chitosan $72 \%$ for $11 \mathrm{kDa}$ chitosan and $69 \%$ for PEG 4000 . Results proved that best release rate was obtained for PVP K30 and PEG 6000. Also the two different 
molecular weights PEG showed a clear difference in the dissolution behavior.

It can be seen that the release profiles of the two marketed drugs were higher than that of pure meloxicam. According to $\mathrm{P}$ values (table 3); all selected SDs showed no significant difference in the release profile of the marketed products except for PEG 6000 SD (SD13) that showed a significant difference than that of Mobic and Moven ${ }^{\circledR}$ and PEG 4000 SD (SD10) that showed significant difference than that of Moven ${ }^{\circledR}$.

\section{Stability studies}

PVP SDs showed after the three months of stability a sticky paste which represented a phase separation and instability state.

Crystallinity was maintained for chitosan $11 \mathrm{kDa}$, PEG SDs; recrystallization was observed for chitosan $16 \mathrm{kDa}$ SD (fig. 7).

Chemical stability (drug content and HPLC analysis) for chitosan and PEG SDs, showed that stability was maintained (fig. 8).
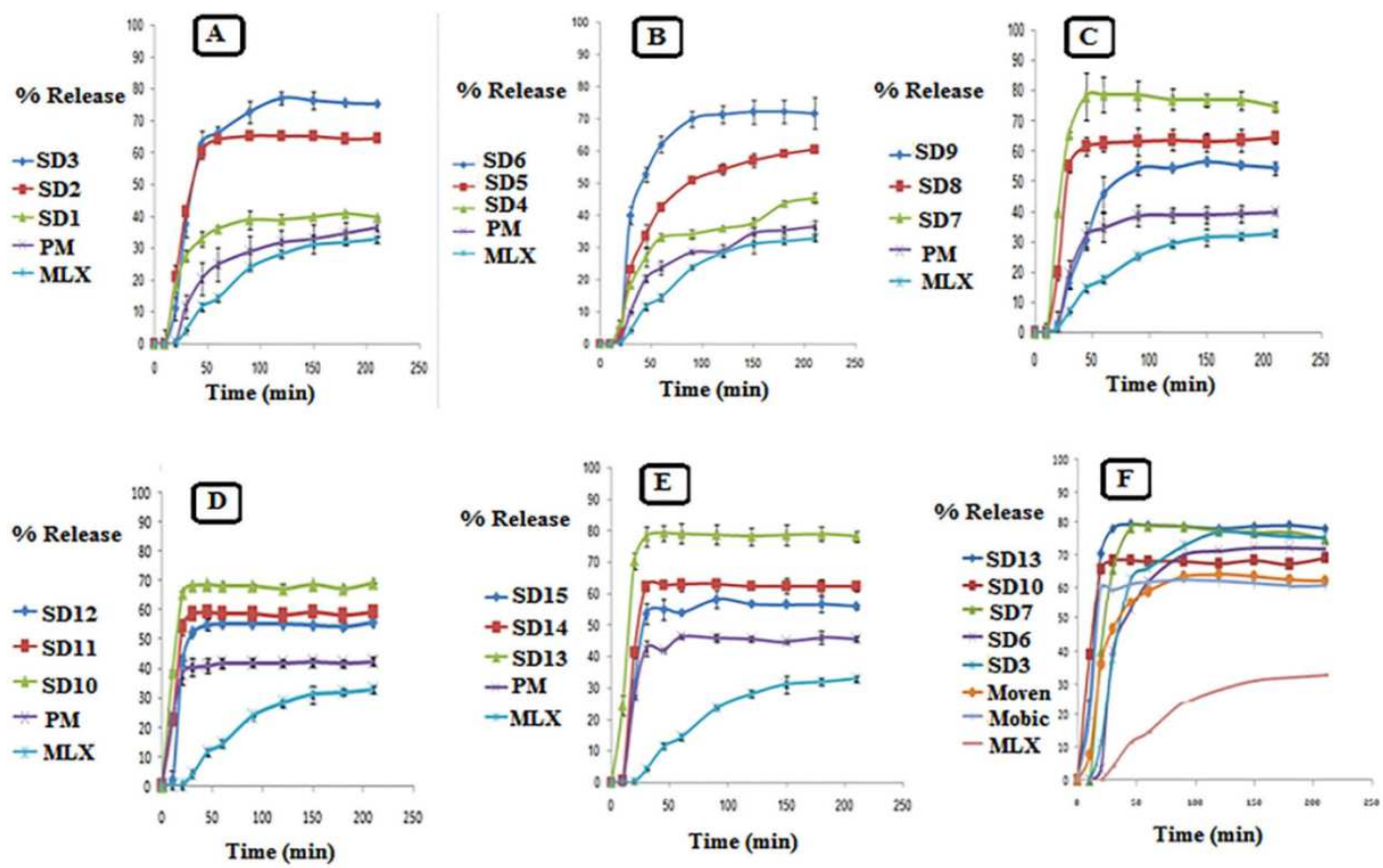

Fig. 6: In vitro dissolution profile of A: meloxicam (MLX), PM of (3:7; meloxicam: chitosan $16 \mathrm{kDa})$, SD1, SD2, and SD3, B: In vitro dissolution profile of meloxicam (MLX), PM of (3:7; meloxicam: chitosan $11 \mathrm{kDa),} \mathrm{SD4,} \mathrm{SD5,} \mathrm{and} \mathrm{SD6,C:} \mathrm{In} \mathrm{vitro} \mathrm{dissolution} \mathrm{profile} \mathrm{of}$ meloxicam (MLX), PM of (3:7; meloxicam: PVP), SD7, SD8, and SD9, D: In vitro dissolution profile of meloxicam (MLX), PM of (3:7; meloxicam: PEG 4000), SD10, SD11, SD12, and E: In vitro dissolution profile of meloxicam (MLX), PM of (3:7; meloxicam: PEG 6000), SD13, SD14, SD15, and F: In vitro dissolution profiles of meloxicam (MLX), Mobic ${ }^{\circledR}$, Moven ${ }^{\circledR}$, SD3, SD5, SD7, SD10, and SD13. Results of dissolution rate are represented as mean of three readings \pm SD. Samples named according to table 1

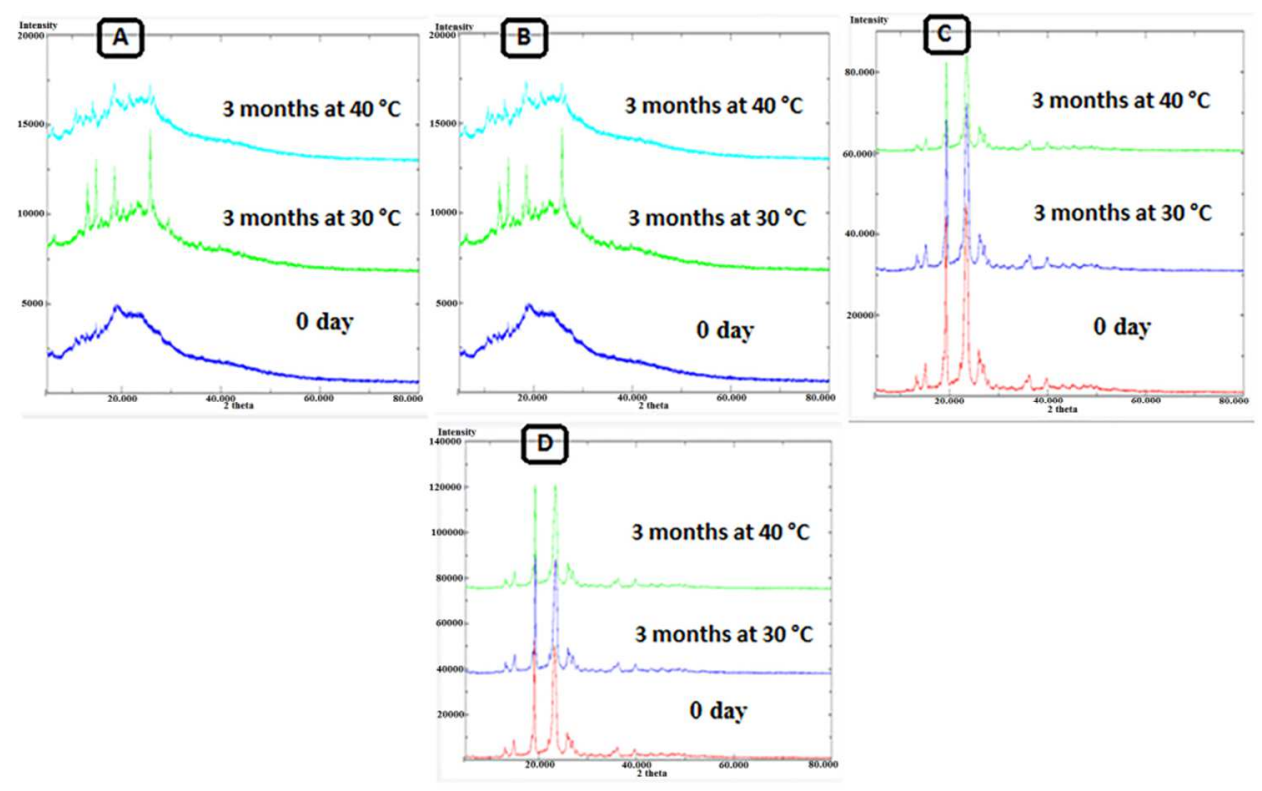

Fig. 7: PXRD analysis for stability studies for A: SD1 at Oday, $3 \mathrm{mo}$ at $30^{\circ} \mathrm{C}$ and $3 \mathrm{mo}$ at $40^{\circ} \mathrm{C}, \mathrm{PXRD}$ analysis for stability studies for $\mathrm{B}$ : SD 4 at $0 \mathrm{~d}, 3 \mathrm{mo}$ at $30^{\circ} \mathrm{C}$ and $3 \mathrm{mo}$ at $40^{\circ} \mathrm{C}$, PXRD analysis for stability studies for C: SD10 at 0 day, $3 \mathrm{mo}$ at $30{ }^{\circ} \mathrm{C}$ and $3 \mathrm{mo}$ at $40{ }^{\circ} \mathrm{C}$, and PXRD analysis for stability studies for D: SD13 at $0 \mathrm{~d}, 3 \mathrm{mo}$ at $30^{\circ} \mathrm{C}$ and $3 \mathrm{mo}$ at $40^{\circ} \mathrm{C}$. Samples named according to table 1 
Table 3: P-Value, $t$-Value and the significant difference of the prepared SDs in comparison to the two selected drugs (Mobic $®$ and Moven $($ ), significant level assumed to be equal to 0.05

\begin{tabular}{|c|c|c|c|c|}
\hline Marketed drug & SD & P-Value & t-Value & Significance \\
\hline \multirow{5}{*}{ Mobic $\AA$} & SD3 & 0.445 & 0.141 & Not Significant \\
\hline & SD5 & 0.298 & 0.539 & Not Significant \\
\hline & SD7 & 0.204 & 0.846 & Not Significant \\
\hline & SD10 & 0.067 & 1.57 & Not Significant \\
\hline & SD13 & 0.018 & 2.25 & Significant \\
\hline \multirow{5}{*}{ Moven $®$} & SD3 & 0.399 & 0.257 & Not Significant \\
\hline & SD5 & 0.483 & 0.042 & Not Significant \\
\hline & SD7 & 0.111 & 1.26 & Not Significant \\
\hline & SD10 & 0.029 & 2.01 & Significant \\
\hline & SD13 & 0.009 & 2.59 & Significant \\
\hline
\end{tabular}

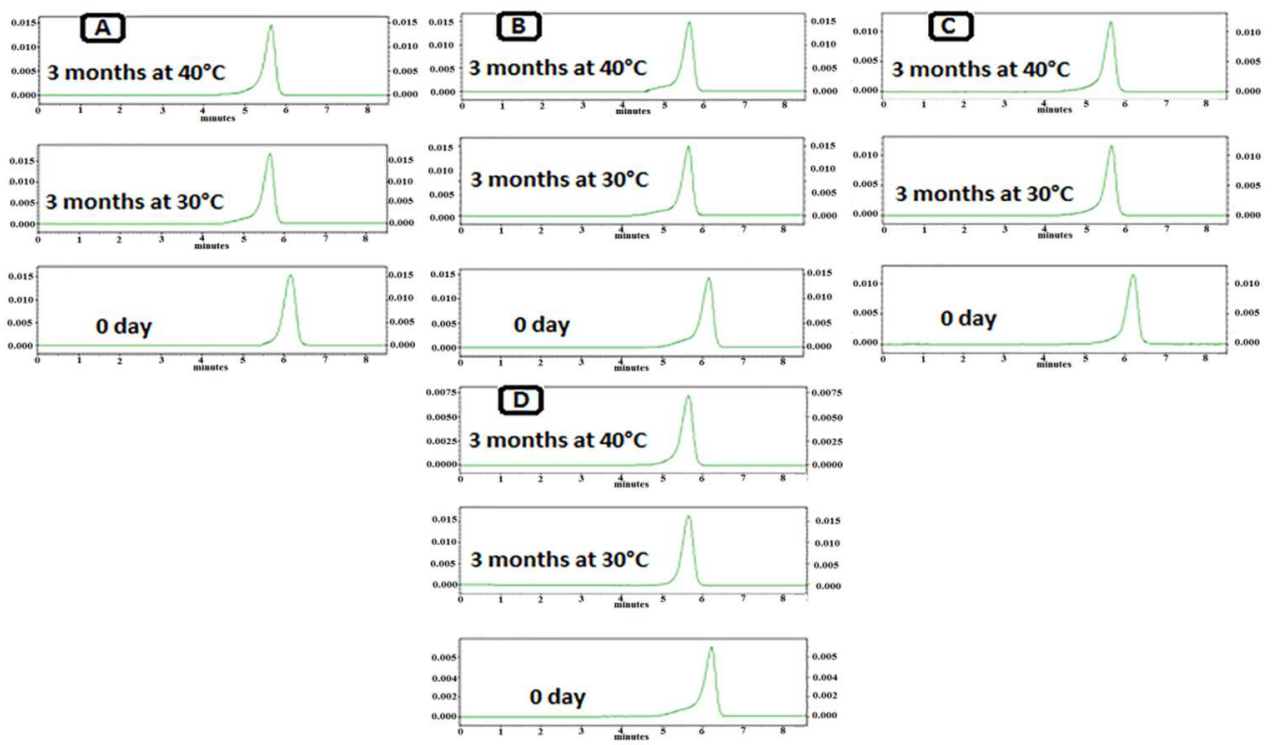

Fig. 8: HPLC analysis results for stability studies of A: SD1 at 0day, $3 \mathrm{mo}$ at $30^{\circ} \mathrm{C}$ and $3 \mathrm{mo}$ at $40{ }^{\circ} \mathrm{C}, \mathrm{HPLC}$ analysis results for stability studies of B: SD4 at Oday, $3 \mathrm{mo}$ at $30^{\circ} \mathrm{C}$ and $3 \mathrm{mo}$ at $40{ }^{\circ} \mathrm{C}$, HPLC analysis results for stability studies of C: SD10 at $0 d a y, 3$ mo at $30^{\circ} \mathrm{C}$ and $3 \mathrm{mo}$ at $40{ }^{\circ} \mathrm{C}$, and HPLC analysis results for stability studies of D: SD13 at $0 \mathrm{~d}, 3 \mathrm{mo}$ at $30^{\circ} \mathrm{C}$ and $3 \mathrm{mo}$ at $40^{\circ} \mathrm{C}$. Samples named according to table 1

\section{DISCUSSION}

Methods employed achieved excellent loading efficiency, and drug content can be related to the method of preparation because the melting method was used for PEGs while solvent evaporation was used for PVP polymer. Exceeding $100 \%$ as for SD11 and SD12 can be related to some loss of polymer amount during preparation procedure.

Meloxicam characterization showed consistency with reported data of the crystalline nature of the pure drug $[3,21,22]$.

For the polymers used, all used polymers matched with published data $[15,17,21,23-30]$. While it can be observed for that higher molecular weight chitosan $(16 \mathrm{kDa})$ exhibited more spherical shape. It can be seen that by increasing the molecular weight of chitosan carrier, the flexibility and elasticity would be increased so that these characteristics gave chitosan 16KDa the ability to surround and make a full inclusion of the drug inside it more than that of the lower molecular weight carrier [25].

For PVP K30, the broad endothermic peak that was obtained in the DSC thermogram is correlated to either the loss of water due to the extreme hygroscopic nature of PVP K30 or glass transition temperature as reported [24]. PVP made hydrogen bonding with meloxicam mainly through $\mathrm{N}-\mathrm{H}$ and $\mathrm{C}=\mathrm{O}$ groups [26]. Also, SEM analysis proved irregular rounded spherical shape [27]. The amorphous form was proved in PXRD [28].

Low molecular weight PEG 4000 had a lower endothermic melting peak than that of the PEG 6000[30], without any difference between
FTIR spectra of the two molecular weights $[12,31]$. The morphology of the two molecular weights PEGs appeared as previously reported as irregular crystalline agglomerates [12, 30].

Physicochemical characterization showed a lack of physicochemical interaction between meloxicam and various polymers. The intensity of the peaks decreased due to the dilution effect.

For chitosan SDs, precipitation of meloxicam as an amorphous form was proved using DSC and PXRD results in the ratio (1:9), and in (2:8) for chitosan $16 \mathrm{kDa}$. Chitosan was precipitated as a crystalline form in other ratios. This emphasizes that ability of the polymer to stabilize amorphous structure will depend on polymer type, molecular weight, and ratio. These results are mainly because of polymeric matrix efficiency and drug recrystallization effect. Paula Mura et al. reported the same results with naproxen-chitosan SD in which by increasing the ratio of naproxen the crystallinity was increased [32]. FTIR spectra also proved this with the definite disappearance of the only $\mathrm{N}-\mathrm{H}$ peak of meloxicam (at $3290.3 \mathrm{~cm}^{-1}$ ) for (1:9) ratio, indicating the formation of strong hydrogen bonding while this peak appeared for other ratios. This also was confirmed by SEM analysis, at which the drug was completely incorporated inside chitosan $16 \mathrm{kDa}$ carrier at $(1: 9)$ ratio; while free drug appeared around SDs in other ratios [25, 27,33].

DSC analysis could not be satisfactory for both PVP and PEG. Lack of drug peaks in both PMs and SDs does not necessarily mean precipitation of the drug as amorphous form inside the polymer. It can be seen that the characteristic peak of meloxicam disappeared, this can be related to an overlap with the glass transition 
temperature of PVP [28]. However, for PEG PMs, this can be related to dissolving of meloxicam in the melted carrier during heating. $S$. Biswal et al. [12]. While for PEG SDs, it can be related to precipitation of the drug as an amorphous system or because that meloxicam dissolved in the melted carrier before it reached the fusion point. For FTIR spectra of PVP SDs, there was a disappearance of the three characteristic peaks of meloxicam in the SD of lower meloxicam: PVP ratio. This indicates that PVP and meloxicam have strong hydrogen bonds between them $[26,27,31]$ and precipitation of meloxicam as an amorphous form in PVP prepared SDs. On the other hand, the characteristic peaks of meloxicam appeared in FTIR analysis of PEG SDs confirming its presence as a crystalline form. While a significant decrease in the intensity of $\mathrm{N}-\mathrm{H}$ and $\mathrm{S}=\mathrm{O}$ stretching and vibration peaks and also there was a shift to higher wave number and a decrease in the intensity of $\mathrm{C}=\mathrm{N}$ peak indicating hydrogen bonding between meloxicam and PEG [30].

PEG effect on crystallization could be related to drug type, polymericratio, and the method of preparation as reported by Rajender Guleria et al. [30]. So the reduction in the intensity of the PXRD peaks of meloxicam was due to dilution effect and not to conversion to an amorphous form because these carriers did not show any evidence of meloxicam conversion from crystalline to amorphous form. Also, SEM images showed partial inclusion of the crystalline drug inside the polymers in a particular manner (without aggregation) $[34,35]$.

The dissolution of meloxicam (fig. 6) was relatively low; this might be attributed to the poor wettability and particles agglomeration [1, 36]. Minor enhancement in drug's release was obtained for prepared PMs. This might be attributed to the hydrophilic nature of the polymers used [37].

Significant enhancement of dissolution was observed for chitosan SDs. This can be related to solubility enhancement, wettability improvement, and reduction in crystallinity. Even though increasing chitosan: drug ratio played a crucial role in precipitation of the drug as an amorphous form; it was not the rate determining step in drug release. The ratio of the polymer in SDs showed to play the main determining factor affecting release rate. Release results showed that by decreasing polymeric ratio, the release was increased and that can be related to the reduction in viscosity of the media which will increase the dissolution rate of the drug [20]. Higher molecular weight chitosan (16 kDa) exhibited higher dissolution rate. This can be related to the higher flexibility of the polymeric chain which allows drug incorporation inside [20,38].

Enhancement of dissolution for PVP SDs can be related to the reduction in the crystallinity as well as for the wettability and deaggregation of the drug by decreasing the ratio of meloxicam to PVP [21, 39]. Both PVP and PEG SDs showed an increase in dissolution with increasing polymeric ratio as reported by other researchers [30, 34, 39]. Higher molecular weight (PEG 6000) resulted in higher dissolution rate. This can be related to the higher viscosity which inhibits recrystallization [40].

Based on the R2 values (table 4); chitosan SDs followed Higuchi model, it means that the release for these preparations was mainly in the diffusion process [41]. While the release mechanism of PVPbased SD preparations of different used ratios (SD7-SD9), (according to the R2 value) was apparently based on korsmeyer-peppas models, and as it was mentioned before, the " $n$ " value determined exactly what the mechanism was, and as it was indicated here that at all ratios the mechanism was "super case II "based release which means that at the beginning of the release, PVP wasn't completely hydrated and so the free release would be hindered and the initial release was slow, then the drug would be released freely after the complete hydration/relaxation of PVP. Naveen Ahuja et al. has got the same results with rofecoxib-PVP based SDs, but the mechanism of release was fickian-based [18, 42]. On the other hand, PEG 4000 SDs followed korsmeyer-peppas models, and " $n$ " value showed that the mechanism of release was fickian (diffusion based) except for SD12 that showed non-fickian drug release (diffusion and erosion release) [42]. Also, most PEG 6000 SDs followed korsmeyer-peppas models with the fickian release, except for SD14 and SD15, since it was nonfickian $[12,42]$. Both marketed drugs (Mobic $®$ and Moven $\circledast$ ) followed the korsmeyer-peppas model with a release mechanism of Mobic $\AA$ on fickian diffusion and non-fickian for Moven $®$.

Table 4: Statistical parameters of the prepared SDs and the two selected marketed drugs obtained after fitting with the mathematical dissolution models. Values of the dissolution rate were taken as the mean of three results

\begin{tabular}{|c|c|c|c|c|}
\hline Formula & Zero order R2 & Higushi R2 & Korsmeyer-peppas R2 & n value \\
\hline SD1 & 0.528 & 0.680 & 0.597 & 2.768 \\
\hline SD2 & 0.467 & 0.625 & 0.610 & 4.681 \\
\hline SD3 & 0.587 & 0.757 & 0.711 & 6.354 \\
\hline SD4 & 0.771 & 0.881 & 0.786 & 3.678 \\
\hline SD5 & 0.767 & 0.886 & 0.809 & 5.463 \\
\hline SD6 & 0.601 & 0.746 & 0.733 & 6.259 \\
\hline SD7 & 0.321 & 0.467 & 0.507 & 0.958 \\
\hline SD8 & 0.394 & 0.541 & 0.577 & 0.988 \\
\hline SD9 & 0.687 & 0.817 & 0.821 & 1.0308 \\
\hline SD10 & 0.193 & 0.293 & 0.443 & 0.115 \\
\hline SD11 & 0.203 & 0.310 & 0.455 & 0.200 \\
\hline SD12 & 0.259 & 0.382 & 0.468 & 0.686 \\
\hline SD13 & 0.208 & 0.32 & 0.462 & 0.246 \\
\hline SD14 & 0.262 & 0.39 & 0.466 & 0.877 \\
\hline SD15 & 0.323 & 0.463 & 0.502 & 0.886 \\
\hline Mobic $®$ & 0.177 & 0.285 & 0.428 & 0.243 \\
\hline Moven $®$ & 0.472 & 0.628 & 0.644 & 0.519 \\
\hline
\end{tabular}

PVP failed to maintain the stability in the prepared SDs. Phase separation was evident in the formation of the sticky paste. Such results confirmed the presence of physiochemical incompatibility between meloxicam and PVP K-30 as shown by FTIR results[43]. This excludes PVP formulations. On the other hand, physicochemical stability was proved in both chitosan and PEG SDs while chitosan $16 \mathrm{kDa}$ failed to maintain physical stability by recrystallization of the drug inside.

\section{CONCLUSION}

Results showed enhancement of dissolution rate using chitosan, PVP, and PEGs. Best dissolution rates were obtained for both PVP
K30 and PEG 6000 dispersions, followed by chitosan $16 \mathrm{kDa}$ chitosan $11 \mathrm{kDa}$, and PEG 4000. The amount, molecular weight and the type of the polymer used had a significant effect on the release of the drug from the SD. Increasing polymeric ratio increased dissolution rate except for chitosan which showed opposite results. This can be related to precipitation of the drug as an amorphous form in certain chitosan and PVP SDs while no evidence appeared for PEG SDs. Failure of PVP K30 in the maintenance of stability during storage time was observed while recrystallization of the drug in chitosan SDs which ends with preferences PEG SDs which show the best stability among all. 


\section{ACKNOWLEDGMENT}

The authors acknowledge Deanship of Research at Jordan University of Science and Technology (JUST) for funding this work with fund number $(303 / 2014)$

\section{AUTHORS CONTRIBUTION}

Please note that this work represents MSc theses of Hanan Al-Quraan at Faculty of Pharmacy in Jordan University of Science and Technology (JUST).

Rana Obaidat: Principle investigator (Selection of the drug, polymers, and techniques. Supervise the methods, results, discussion, and writing. Editing of the manuscript. This author was the primary advisor for MSc theses.

Bashar Al-Taani: Co-investigator (Help in results analysis and discussion). This author is the Co-Advisor for the MSc theses.

Hanan Al-Quraan: Perform technical work which includes preparation of the dispersions, analysis of the samples, and conduct scientific analysis on results.

\section{CONFLICT OF INTERESTS}

\section{Declared none}

\section{REFERENCES}

1. Awashti S, Kumar T, Manisha P, Preeti Y, Kumar S. Development of meloxicam formulations utilizing ternary complexation for solubility enhancement. Pak J Pharm Sci 2011;24:533-8.

2. Kulkarni U, Patil B, Hariprasanna RC, Borgaonkar P, Hogade M, Rabbani G. Formulation and development of fast dissolving meloxicam tablets by solid dispersion technique: for the effective treatment of dental pain. Int J Curr Pharm Res 2010;2:82-5.

3. Ghareeb M, Abdulrasool A, Hussein A, Noordin M. Kneading technique for preparation of binary solid dispersion of meloxicam with poloxamer 188. AAPS PharmSciTech 2009;10:1206-16.

4. Samprasit W, Akkaramongkolporn P, Ngawhirunpat T, Rojanarata T, Opanasopit P. Meloxicam taste-masked oral disintegrating tablet with dissolution enhanced by ion exchange resins and cyclodextrin. AAPS PharmSciTech 2013;14:1118-26.

5. Hu L, Gu D, Hu Q, Shi Y, Gao N. Investigation of solid dispersion of atorvastatin calcium in polyethylene glycol 6000 and polyvinylpyrrolidone. Tropical J Pharm Res 2014;13:835.

6. Ohara $\mathrm{T}$, Kitamura $\mathrm{S}$, Kitagawa $\mathrm{T}$, Terada K. Dissolution mechanism of poorly water-soluble drug from extended release solid dispersion system with ethylcellulose and hydroxypropylmethylcellulose. Int J Pharm 2005;302:95-102.

7. More S, Sontakke S. Solubility enhancement of gliclazide by solid dispersion method. Asian J Pharm Clin Res 2013;6 Suppl 5:91-8

8. Kurmi R, Mishra D, Jain D. Solid dispersion: a novel means of solubility enhancement. J Crit Rev 2016;3:1-8.

9. Mendhe A, Kharwade R, Mahajan U. Dissolution enhancement of poorly water-soluble drug by cyclodextrinsinclusion complexation. Int J Appl Pharm 2016;8:60-5.

10. Rinaudo M. Chitin and chitosan: properties and applications. Prog Polym Sci 2006;31:603-32.

11. Zhang $X$, Sun N, Wu B, Lu Y, Guan T, Wu W. Physical characterization of lansoprazole/PVP solid dispersion prepared by fluid-bed coating technique. Powder Technol 2008;182:480-5.

12. Biswal S, Sahoo J, Murthy P, Giradkar R, Avari J. Enhancement of dissolution rate of gliclazide using solid dispersions. With polyethylene glycol 6000. AAPS PharmSciTech 2008;9:563-70.

13. Obaidat R, Al-Jbour N, Al-Sou'd K, Sweidan K, Al-Remawi M, Badwan A. Some physico-chemical properties of low molecular weight chitosans and their relationship to conformation in aqueous solution. J Solution Chem 2010;39:575-88.

14. Induri M, Mantripragada B, Yejella R, Kunda P, Nannapaneni $P$, Boddu R. Dissolution studies and quantification of meloxicam in tablet dosage form by spectrophotometry. Pak J Pharm Sci 2012;25:283-7.
15. Obaidat R, Tashtoush B, Awad A, Al Bustami R. Using supercritical fluid technology (SFT) in preparation of tacrolimus solid dispersions. AAPS PharmSciTech 2017;18:481-93.

16. Oliveira E, Azevedo R, Bonfilio R, Oliveira D, Ribeiro G, Araújo M. Dissolution test optimization for meloxicam in the tablet pharmaceutical form. Brazilian J Pharm Sci 2009;45:68-73.

17. Obaidat R, Tashtoush B, Bayan M, Al Bustami R, Alnaief M. Drying using supercritical fluid technology as a potential method for preparation of chitosan aerogel microparticles. AAPS PharmSciTech 2015;16:1235-44.

18. Costa P, Lobo J. Modeling and comparison of dissolution profiles. Eur J Pharm Sci 2001;13:123-33.

19. Sinha P, Jeswani R, Topagi K, Damale M. A validated RP-HPLC method for determination of meloxicam in the presence of its impurities. Int J PharmTech Res 2009;1:1051-60.

20. Gonza Lez-Rodrı Guez M, Holgado M, Mah, Sa Nchez-Lafuente C, Rabasco A, Fini A. Alginate/Chitosan particulate systems for sodium diclofenac release. Int J Pharm 2002;232:225-34.

21. El-Badry M, Fathy M. Enhancement of the dissolution and permeation rates of meloxicam by formation of its freeze-dried solid dispersions in polyvinylpyrrolidone K-30. Drug Dev Ind Pharm 2006;32:141-5.

22. Saleem M, Bala S. Formulation and evaluation of meloxicam solid dispersion incorporated topical gels. Int J Pharma Bio Sci 2010;1:1-9.

23. Ujang Z, Diah M, Abdul Rashid A, Halim A. The development, characterization and application of water soluble chitosan. Biotechnol Polymers 2011;6:110-27.

24. Frizon F, Eloy J, Donaduzzi C, Mitsui M, Marchetti J. Dissolution rate enhancement of loratadine in polyvinylpyrrolidone K-30 solid dispersions by solvent methods. Powder Technol 2013;235:532-9.

25. Ko J, Park H, Hwang S, Park J, Lee J. Preparation and characterization of chitosan microparticles intended for controlled drug delivery. Int J Pharm 2002;249:165.

26. Paradkar A, Ambike A, Jadhav B, Mahadik K. Characterization of curcumin-PVP solid dispersion obtained by spray drying. Int J Pharm 2004;271:1-2.

27. Fini A, Cavallari C, Ospitali F. Raman and thermal analysis of indomethacin/PVP solid dispersion enteric microparticles. Eur J Pharm Biopharm 2008;70:409-20.

28. Abdelrazek E, Ragab H, Abdelaziz M. Physical characterization of poly (Vinyl Pyrrolidone) and gelatin blend films doped with magnesium chloride. Plastic Polymer Technol (PAPT) 2013;2:1-8.

29. Bolourchiana N, Mahboobian M, Dadashzadeh S. The effect of PEG molecular weights on dissolution behavior of simvastatin in solid dispersions. Iranian J Pharm Res 2013;12:12-20.

30. Guleria R, Kaith N, Singh R. PEG based SDs of gliclazide: a comparative study. Int J Pharm Pharm Sci 2012;4:507-11.

31. Shashikant D, Barhate GAS, Ankit S Sharma, Prashant DN. Formulation of fast dissolving tablets of Meloxicam. J Pharm Res 2009;2:646-50.

32. Mura P, Zerrouk N, Mennini N, Maestrelli F, Chemtob C Development and characterization of naproxen-chitosan solid systems with improved drug dissolution properties. Eur J Pharm Sci 2003;19:67-75.

33. Gong K, Darr J, Rehman I. Supercritical fluid assisted impregnation of indomethacin into chitosan thermosets forcontrolled release applications. Int J Pharm 2006;315:93-8.

34. Gurusamy S, Kumar V, Mishra D. Preparation, characterization and in vitro dissolution studies of solid dispersion of meloxicam with PEG 6000. Yakugaku Zasshi 2006;126:657-64.

35. Pathak D, Dahiya S, Pathak K. Solid dispersion of meloxicam: factorially designed dosage form for geriatric population. Acta Pharm 2008;58:99-110.

36. Gurusamy S, Kumar V, Mishra D. Preparation and evaluation of solid dispersion of meloxicam with skimmed milk. Yakugaku Zasshi 2006;126:93-7.

37. Shiraishi S, Arahira M, Imai T, Otagiri M. Enhancement of dissolution rates of several drugs by low-molecular chitosan and alginate. Chem Pharm Bull 1990;38:185-7.

38. Bansal V, Kumar P, Sharma N, Pal O, Malviya R. Applications of chitosan and chitosan derivatives in drug delivery. Adv Biol Res (Rennes) 2011;5:28-37. 
39. Craig D. The mechanisms of drug release from solid dispersions in water-soluble polymers. Int J Pharm 2002;231:131-44.

40. Leuner C, Dressman J. Improving drug solubility for oral delivery using solid dispersions. Eur J Pharm Biopharm 2002;50:47-60.

41. Jameela S, Kumary T, Lal A, Jayakrishnan A. Progesteroneloaded chitosan microspheres: a long acting biodegradable controlled delivery system. J Controlled Release 1998;52:1724.

42. Ahuja N, Katare 0, Singh B. Studies on dissolution enhancement and mathematical modeling of drug release of a poorly water- soluble drug using water-soluble carriers. Eur J Pharm Biopharm 2007;65:26-3.

43. Caron V, Hu Y, Tajber L, Erxleben A, Corrigan O, Mcardle P, et al. Amorphous solid dispersions of sulfonamide/Soluplus $\AA$ and sulfonamide/PVP prepared by ball milling. AAPS PharmSciTech 2013;14:464-74

\section{How to cite this article}

- Rana Obaidat, Bashar Al-Taani, Hanan AL-Quraan. Effect of selected polymers on dissolution and stabilization of amorphous form of meloxicam. Int J Pharm Pharm Sci 2017;9(9):33-42. 